\title{
Manganese(II) octacyanotungstate(V)-based magnet containing a noncoordinated aromatic molecule
}

Toshinori Kashiwagi, ${ }^{\dagger}$ Shin-ichi Ohkoshi, $, \star \dagger, \ddagger$ Hidetake Seino, $§$ Yasushi Mizobe, $\S$ and Kazuhito Hashimoto*,†

${ }^{\dagger}$ Research Center for Advanced Science and Technology, The University of Tokyo, 4-6-1 Komaba, Meguro-ku, Tokyo 153-8904, Japan

PRESTO, JST, 4-1-8 Honcho Kawaguchi, Saitama, Japan

$\S$ Institute of Industrial Science, The University of Tokyo,

4-6-1 Komaba, Meguro-ku, Tokyo 153-8505, Japan

e-mail: ohkoshi@light.t.u-tokyo.ac.jp, hashimoto@,light.t.u-tokyo.ac.jp

SUPPORTING INFORMATION

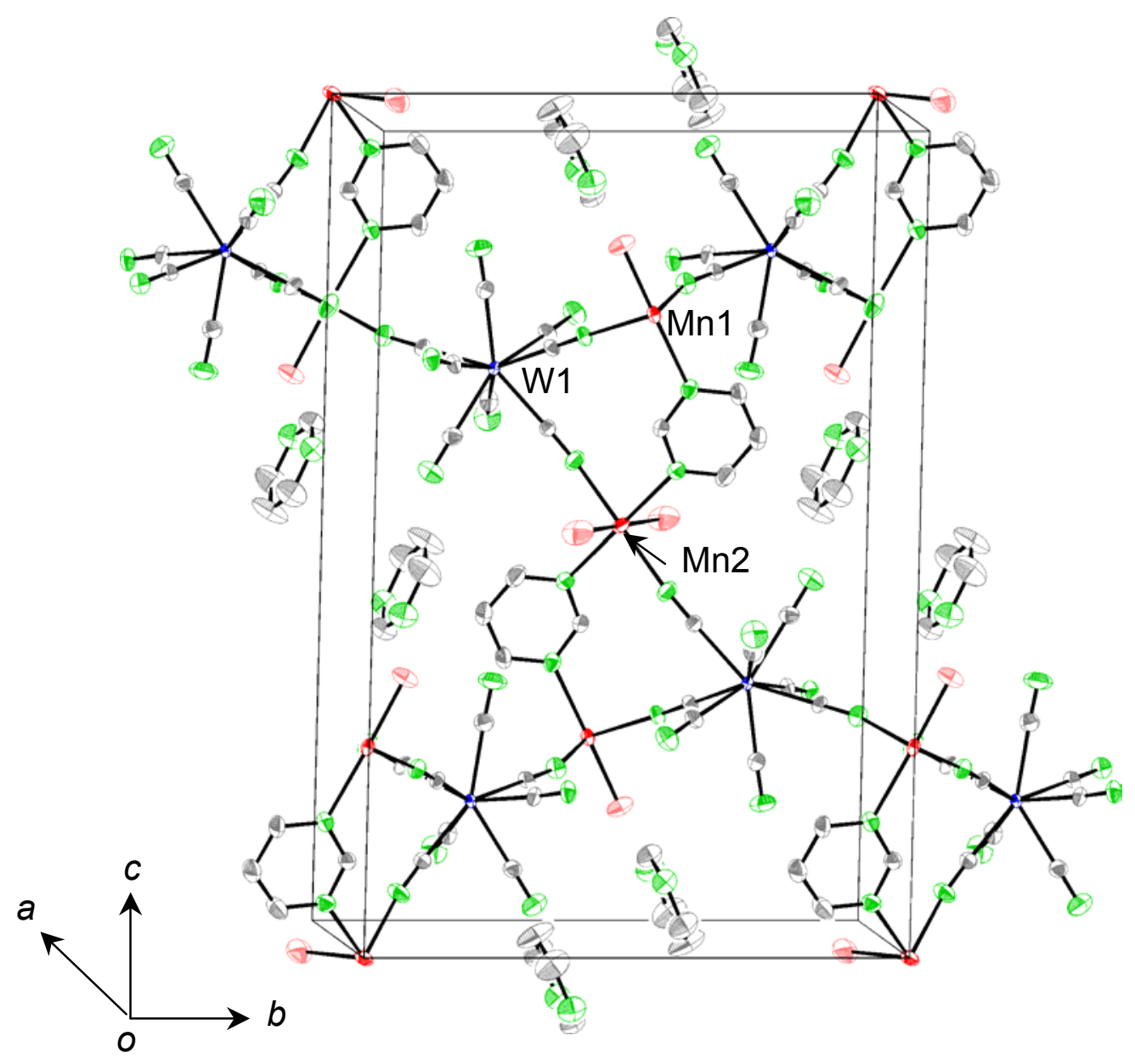

Figure S1. A view of the unit cell of $\left[\left\{\mathrm{Mn}^{\mathrm{II}}(\text { pyrimidine })\left(\mathrm{H}_{2} \mathrm{O}\right)\right\}_{2}\left\{\mathrm{Mn}^{\mathrm{II}}\left(\mathrm{H}_{2} \mathrm{O}\right)_{2}\right\}-\right.$ $\left.\left\{\mathrm{W}^{\mathrm{V}}(\mathrm{CN})_{8}\right\}_{2}\right]$ (pyrimidine) $)_{2} \cdot \mathbf{2} \mathrm{H}_{2} \mathrm{O}$. 


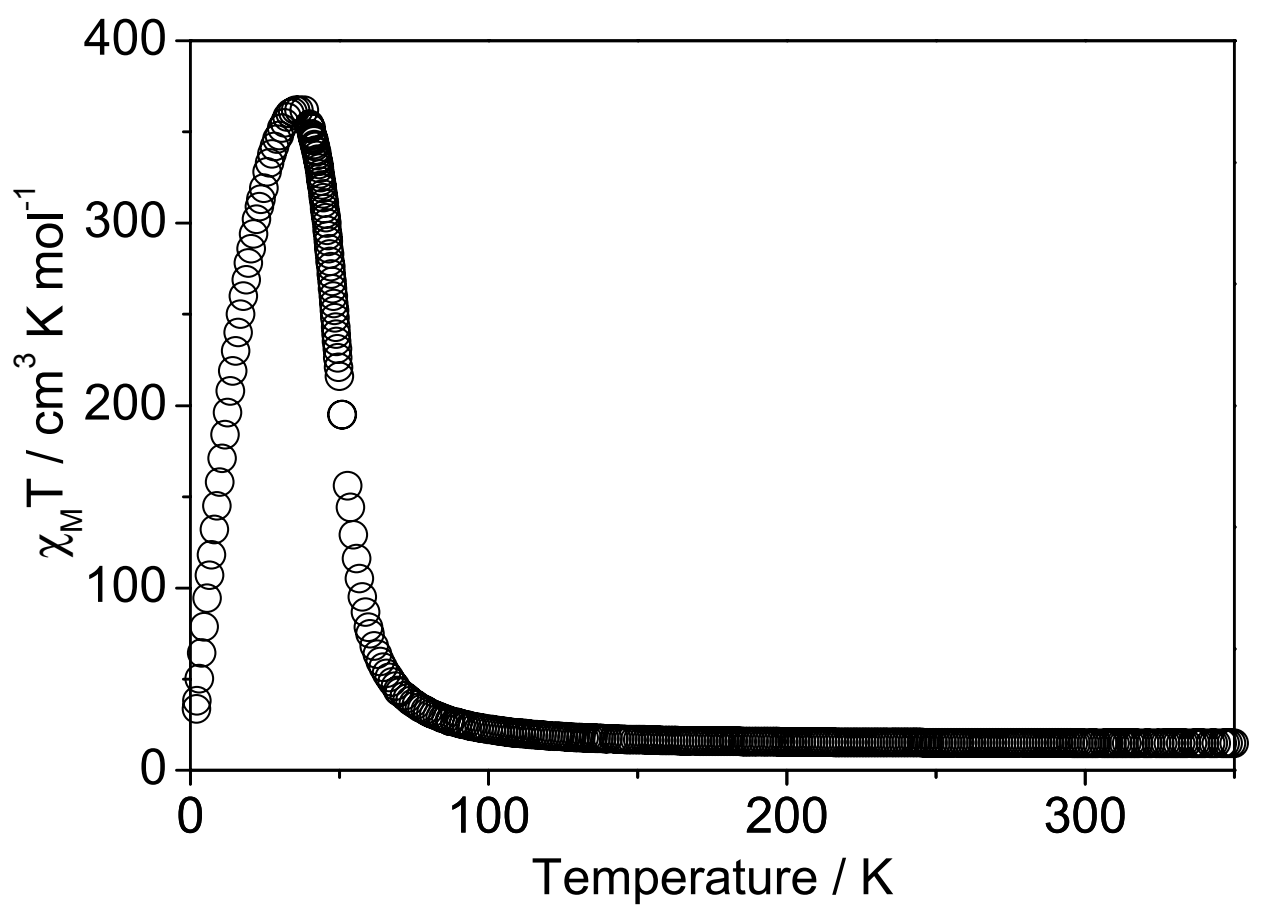

Figure S2. Temperature dependence of $\chi_{M} T$ value of $\left[\left\{\mathrm{Mn}^{\mathrm{II}}(\text { pyrimidine })\left(\mathrm{H}_{2} \mathrm{O}\right)\right\}_{2^{-}}\right.$ $\left.\left\{\mathrm{Mn}^{\mathrm{II}}\left(\mathrm{H}_{2} \mathrm{O}\right)_{2}\right\}\left\{\mathrm{Wv}(\mathrm{CN})_{8}\right\}_{2}\right]$ (pyrimidine $)_{2} \cdot 2 \mathrm{H}_{2} \mathrm{O}$.

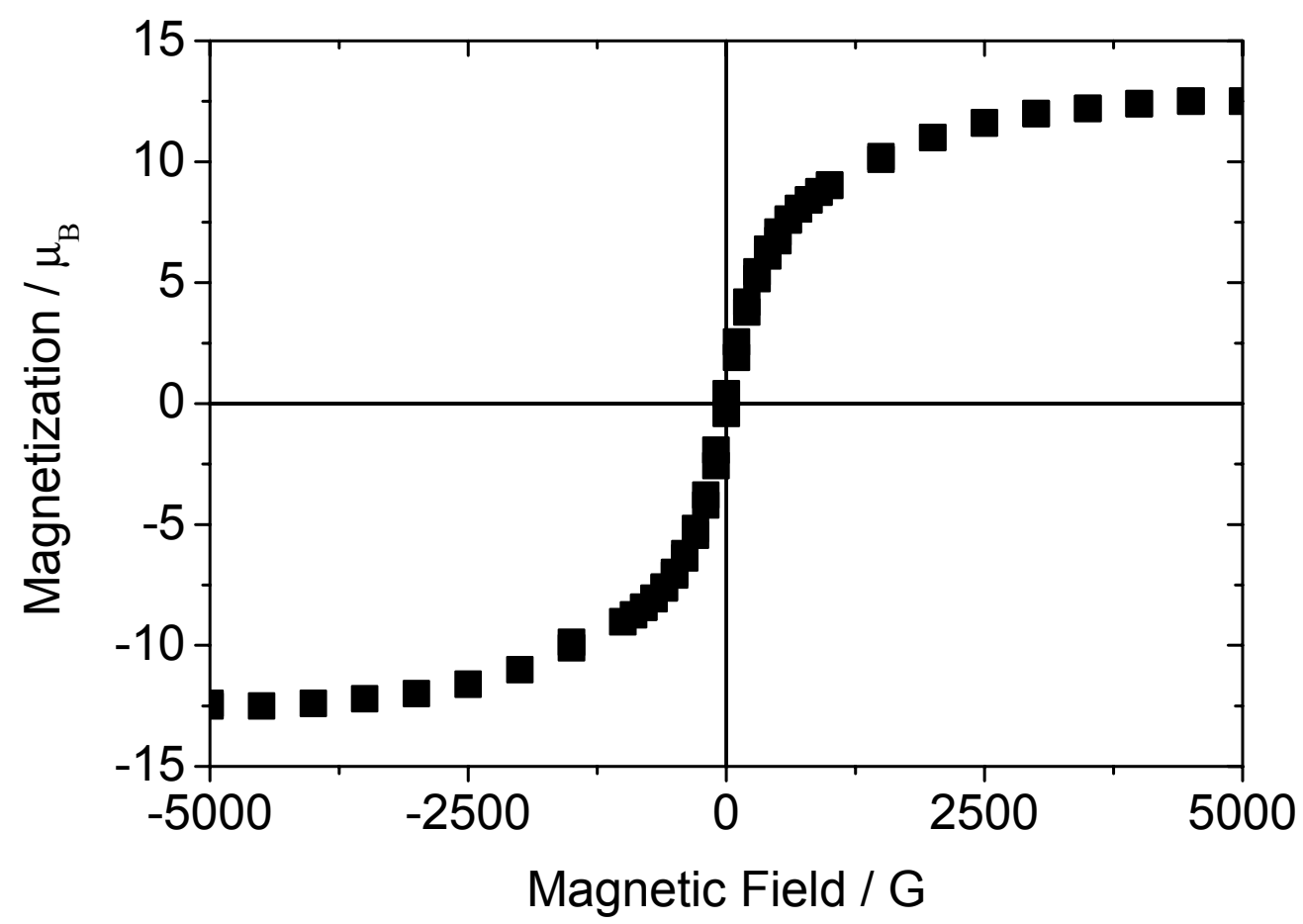

Figure S3. The magnetic hysteresis loop of $\left[\left\{\mathrm{Mn}^{\mathrm{II}}(\text { pyrimidine })\left(\mathrm{H}_{2} \mathrm{O}\right)\right\}_{2}\left\{\mathrm{Mn}^{\mathrm{II}}\left(\mathrm{H}_{2} \mathrm{O}\right)_{2}\right\}-\right.$ $\left.\left\{\mathrm{W}^{\mathrm{V}}(\mathrm{CN})_{8}\right\}_{2}\right]$ (pyrimidine) $)_{2} \cdot \mathbf{2} \mathrm{H}_{2} \mathrm{O}$. 
(a)

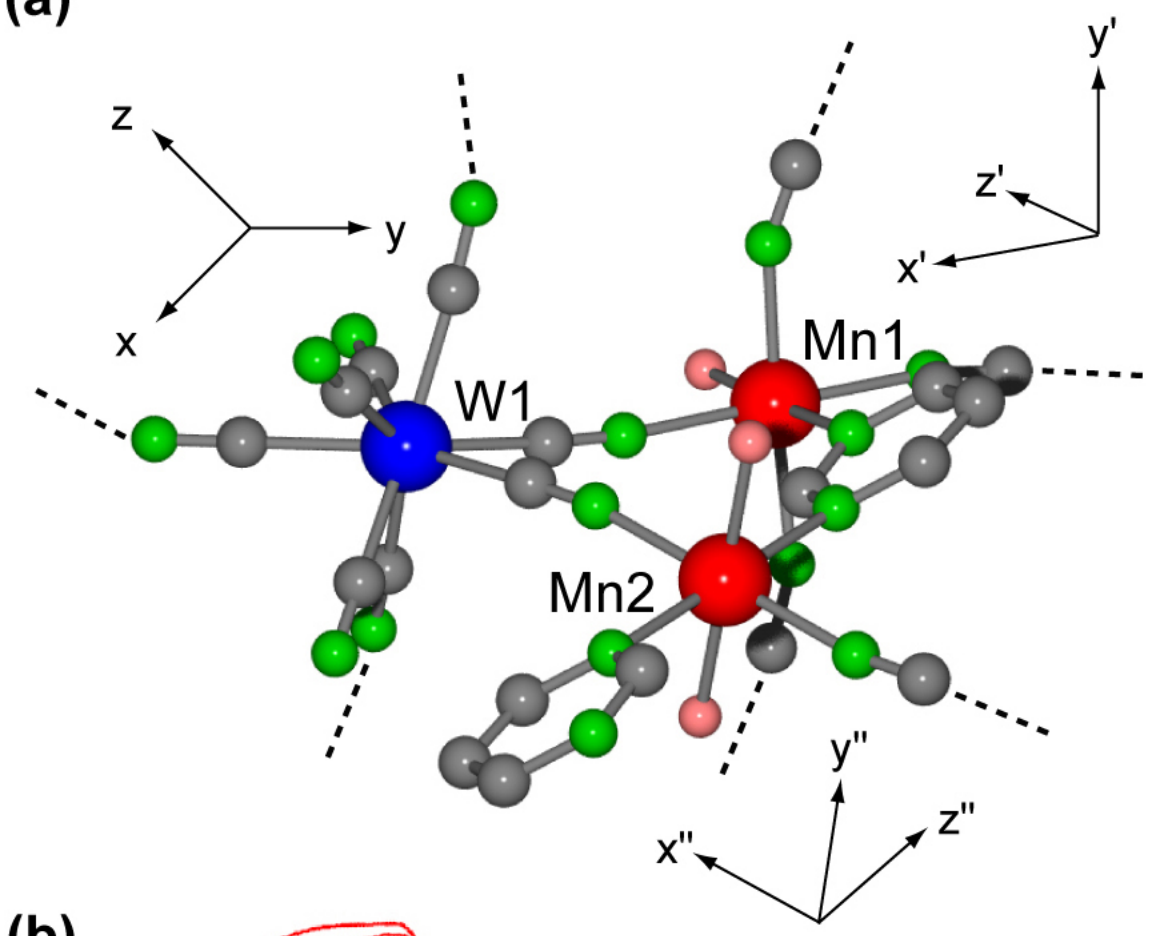

(b)

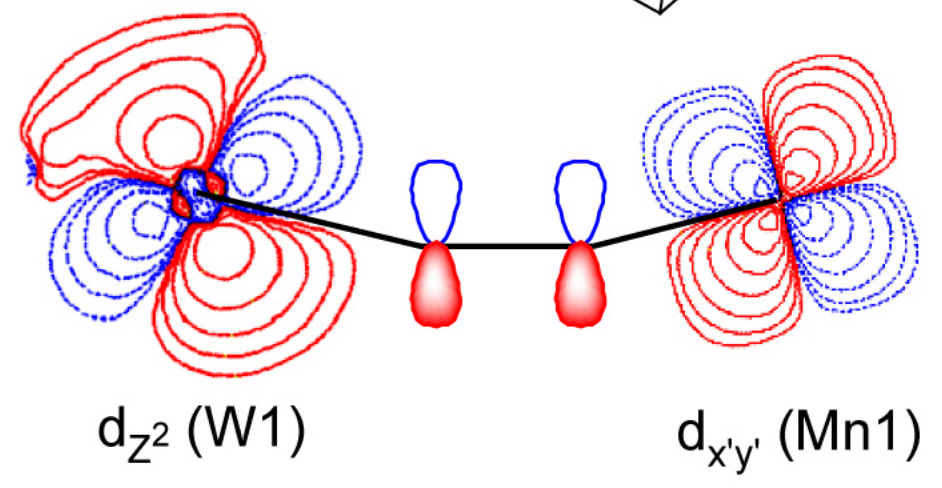

(c)

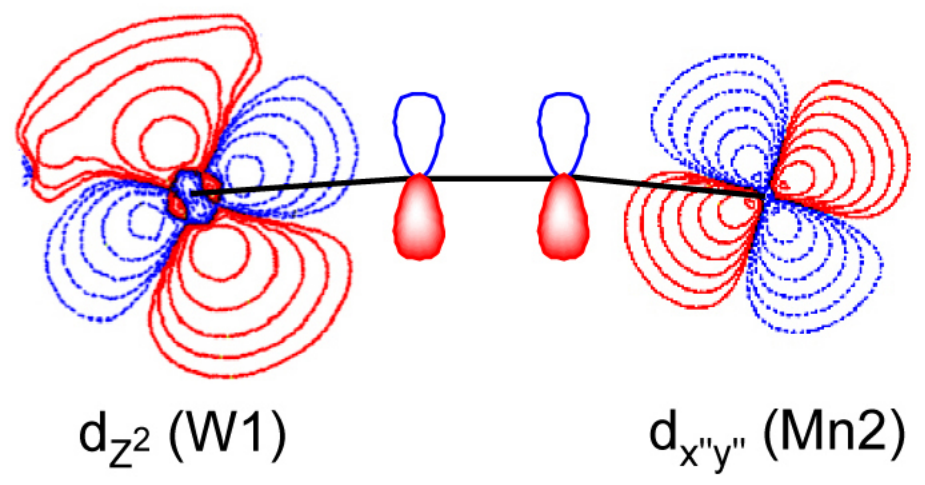

Figure S4. Schematic illustration of the superexchange pathways between $\mathrm{W}^{\mathrm{V}}$ and $\mathrm{Mn}^{\mathrm{II}}$ (Mn1 and Mn2) site through the bridged cyanide. (a) The geometric structures and molecular symmetric axes. (b) The magnetic orbitals on $\mathrm{W}(\mathrm{CN})_{8}$ and $\operatorname{Mn} 1(\mathrm{CN})_{4}\left(\mathrm{H}_{2} \mathrm{O}\right)$ (pyrimidine) units. (c) The magnetic orbitals on $\mathrm{W}(\mathrm{CN})_{8}$ and $\mathrm{Mn} 2(\mathrm{CN})_{2}\left(\mathrm{H}_{2} \mathrm{O}\right)_{2}(\text { pyrimidine })_{2}$ units. 
The coordination geometries of the $\mathrm{W}$ and $\mathrm{Mn}$ sites are $\mathrm{C}_{2 \mathrm{v}}$ and $\mathrm{D}_{4 \mathrm{~h}}$, respectively (Figure S4a). DV-X $\alpha$ calculation for the $\mathrm{W}$ and $\mathrm{Mn}$ units suggests that one $5 \mathrm{~d}$ orbital $\left(\mathrm{A}_{1}\right)$ of $\mathrm{W}$ and five $3 \mathrm{~d}$ orbitals $\left(\mathrm{B}_{1 \mathrm{~g}}, \mathrm{~B}_{2 \mathrm{~g}}, \mathrm{~A}_{2 \mathrm{~g}}\right.$, and two $\mathrm{A}_{1 \mathrm{~g}}$ ) of $\mathrm{Mn} 1$ are magnetic orbitals. Considering the directions of magnetic orbitals and the molecular symmetrical axes of the $\mathrm{W}$ and $\mathrm{Mn} 1$ sites, the antiferromagnetic superexchange interaction in the grid layer is expected to operate between the $A_{1}$

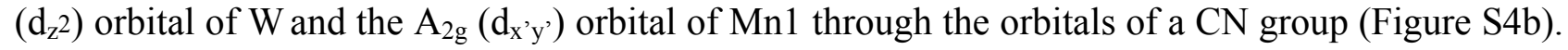
A magnetic interaction between the $A_{1}\left(d_{z^{2}}\right)$ orbital of $W$ and the $A_{2 g}\left(d_{x " y}\right.$ ) orbital of Mn2 through the cyano-bridge is also expected to be antiferromagnetic (Figure S4c). Hence, this compound shows ferrimagnetism and $T_{C}$ value of $47 \mathrm{~K}$ is higher than that of $\mathrm{Cs}^{\mathrm{I}}\left[\left\{\mathrm{Mn}^{\mathrm{II}}(3 \text {-cyanopyridine })_{2}\left\{\mathrm{~W}^{\mathrm{V}}(\mathrm{CN})_{8}\right\}\right\} \cdot \mathrm{H}_{2} \mathrm{O} \quad\left(T_{\mathrm{C}}=35 \mathrm{~K}\right)\right.$ because the magnetic interaction between layers through the Mn2 pillar complex is added. As for the magnetic coupling between Mn1 and Mn2 through coordinated pyrimidine molecule, its coupling constant is considered to be very small because the distance through bonds is too long, i.e., $d(\mathrm{Mn} 1-\mathrm{N} 9-\mathrm{C} 9-\mathrm{N} 10-\mathrm{Mn} 2)=7.31 \AA$. 